\title{
TEORÍAS GEOPOLÍTICAS
}

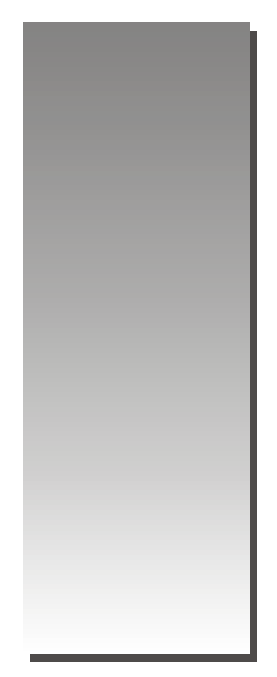

VÍCTOR GIUDICE BACA*

E-mail:vgiudiceb@unmsm.edu.pe

\begin{abstract}
RESUMEN
El presente estudio expone seis teorías geopolíticas pertenecientes a Alfred Mahan, Halford Mackinder, James Fairgrieve, Nicolás Spykman, Alexander Seversky y Samuel Cohen.

Se considera que la Teoría del Poder Marítimo de Mahan (1890) fue ampliada por la Teoría del Poder Terrestre de Mackinder (1905). James Fairgrieve (1915) diseñó un mundo basado en Zonas de Presión, Zonas de Conflicto y Países Buffer o países diseñados para separar a las grandes potencias entre sí. Nepal de la India, Finlandia de los Países Nórdicos, Bélgica separó la proximidad de Alemania a Inglaterra y flanco norte de Francia. La Teoría del Poder Aéreo (Seversky 1950) nació ante la ruptura de los bloqueos marítimos y terrestres por la aviación soviética. Samuel Cohen (Estados Unidos, 1990 y 2002) creó La Teoría de la Jerarquía de los Espacios Globales apropiada para un mundo tripolar constituido por los Estados Unidos, una Unión Europea de 25 países y el Pacífico (Rusia, China, Japón). Spykman (USA, 1950), estableció La Teoría del Perímetro de Seguridad de los Estados Unidos.

Palabras clave: Geopolítica, Potencias, Teorías Geopolíticas.
\end{abstract}

\section{ABSTRACT}

The present study exposes six geopolitical theories belonging to Alfred Mahamçn, Halford Mackinder, James Fairgrieve, Nicolas Spykman, Alexander Seversky and Samuel Cohen.

It is considered that the Theory of the Marine Power of Mahan (1890) was enlarged by the Theory of the Terrestrial Power of Mackinder (1905). James Fairgrieve (1915) designed a world based on Areas of Pressure, Areas of Conflict and Countries Buffer or countries designed to separate to each other to the big powers. Nepal from the India, Finland of the Nordic Countries, Belgium separated the vicinity from Germany to England and north flank of France. The theory of the Air Power (Seversky 1959) was born before the rupture of the marine and terrestrial blockades for the Soviet aviation. Samuel Cohen (USA, 1990 and 2002) created the Theory of the Hierarchy of the appropriate Global Sapces for a tripolar world constituted by the United States, the European Union of 25 countries and the Pacific (Russia, China, Japan) . Spykman (USA, 1950) established the Theory of the Perimeter of Security of the United States.

Keywords: Geopolitics, Powers, Geopolitical Theories.

Profesor principal de la Facultad de Ciencias Económicas de la Universidad Nacional Mayor de San Marcos. 


\section{INTRODUCCIÓN}

Estados Unidos y Gran Bretaña han tenido la visión del poder mundial. El primero en el siglo XX e Inglaterra desde 1700 hasta 1945.

Gran Bretaña desarrolló sus teorías del dominio marítimo y construyó con estas teorías su poder naval y más tarde su dominio en los mares, estrechos y pasos. Creó países «tapón» (Bélgica, Malasia, Singapur, Nepal, Kuwait en 1936, y más tarde el Peñón de Gibraltar que controlaba la salida del Mediterráneo); también controló el Paso de Suez, paso del Océano Atlántico al Mar Mediterráneo, y el Océano Pacífico. Al centro del Mediterráneo también ocupó la pequeña pero estratégica República de Malta (para descanso, mantenimiento de naves y punto de agua).

La visión de Inglaterra como potencia la delineó ya Adam Smith (1776) en la Riqueza de las Naciones. Inglaterra se había fortalecido al colonizar Irlanda y convertirla en gran productora de alimentos para la industrialización de Londres, Liverpool y Manchester. Argentina, Canadá y Australia le proporcionaron la lana; y Perú y Egipto le brindaron algodón.

Según el Dr. Yépez del Castillo, la agricultura de Inglaterra empezó a declinar cuando se agotaron los fertilizantes que poseía en África (1840). Por ello, cuando aparecieron el guano y el salitre en el Perú, Inglaterra empleó la guerra indirecta (Chile vs. Perú), lo que le permitió apoderarse de ambos recursos.

El salitre, además de buen fertilizante, era un insumo clave para la pólvora, los cañones y las guerras coloniales.

El comercio de textiles fue el principal producto de exportación de Inglaterra durante casi 185 años (1700-1885), prohibiendo que se exportara maquinaria textil a las colonias o países competidores.

El geógrafo francés Ives Lacoste define la geopolítica como la disciplina que estudia las rivalidades por los territorios, países y continentes.

- Países o potencias globales: Visión estratégica. Inglaterra, Estados Unidos, Alemania, Francia, Rusia y aún la pequeña Holanda, han sido o continúan siendo potencias globales. Las potencias globales poseen una visión de poder y posicionamiento en los continentes y en torno a los principales yacimientos de gas, petróleo y minerales estratégicos (tungs- teno, zinc, vanadio, aluminio, cromo, níquel, indio, uranio, etc.). La visión estratégica es asegurarse las reservas escasas de gas, petróleo y minerales industriales para el crecimiento de sus países.

- Estrategias geopolíticas de dos potencias. Las potencias mundiales no disponen de grandes reservas de energía. Irak posee seis veces más petróleo que Estados Unidos. Inglaterra sólo tiene petróleo para diez años y Estados Unidos para once años. Irak posee petróleo para abastecer sólo y sólo a Estados Unidos por cincuenta años. Venezuela posee 15 depósitos de gas del tamaño de Camisea. Venezuela posee gas para 400 años y petróleo para 64 años.

\section{PRINCIPALES TEORÍAS GEOPOLÍTICAS}

- Alfred Mahan. Norteamericano nacido en1890. Mahan, a finales del siglo XIX, consideraba que debido a que Gran Bretaña tenía bajo su control las principales vías marítimas entre Europa, Asia y África y las rutas comerciales de los Océanos Atlántico, Pacífico e Indico. Su país debía tomar posesión de Hawaii como puerto estratégico ante alguna invasión de Asia promoviendo la construcción de un canal en el Istmo de Panamá, que conectara las aguas del Atlántico con las del Pacífico.

- Halford Mackinder. Inglés, geógrafo y catedrático de Oxford, construyó una teoría (visión) geopolítica apropiada a Inglaterra. En 1905 expuso que la era de las potencias marítimas llegaba a su fin. Consideró que el siglo XX sería el siglo del poder terrestre. Mahan consideraba que el ferrocarril había unido los puertos de Europa con los Urales (Rusia) y Asia. Eurasia había sido creada por las densas redes de ferrocarriles unidos a los puertos comerciales y había surgido un territorio que determinaba un nuevo poder terrestre distribuido entre HamburgoAmsterdam, Moscú y el Mar Negro, repleto de petróleo. Ese nuevo territorio "pivote» era un nuevo poder o Tierra Corazón (Heartland). Mackinder orientó a Inglaterra a controlar los ferrocarriles de Europa y evitar una alianza Moscú-Berlín-Tokio, que dominarían Eurasia, excluyendo a Inglaterra (1905).

Makinder logró que después de la guerra (1919) se crearan Estados «Buffer» (tapones) 
como Polonia y Yugoslavia, a fin de separar a Rusia de Europa y «empujar a Rusia hacia el Asia». Alemania fue reducida, al quedar parte de su territorio y población en Polonia.

- James Fairgrieve. También geógrafo inglés y discípulo de Mackinder, construyó un mundo más avanzado: un mundo de "Zonas de Presión» (1915) también consideradas «Crush Zones», zona que se ubicaría entre el Heartland Moscú-Alemania-Tokio. En la Guerra Fría se formaron Suecia, Finlandia (en el Norte) y Holanda, Bélgica, Luxemburgo, Suiza, Afganistán, Korea del sur y Taiwán, como estados pequeños que separaban las grandes potencias. Nepal fue creada para separar a China de la India. Pakistán y Bangladesh debilitaron a la India en los flancos este y oeste.

- Nicolás Spykman. Norteamericano, creó el «Realismo Político», es decir negociar reconociendo territorios ajenos y propios. Consideró que las regiones pivote de Makinder habían entrado en decadencia hacia 1945 y propuso el poder los países con «Doble Frente», es decir países bimarítimos, que ponen en contacto el centro de los continentes con los mares, en sus bordes este, oeste, norte y sur. Se creó la teoría de «RIMLAND» o Teoría de la Circunnavegación. Spykman creó la Teoría del Perímetro de Seguridad de los Estados Unidos que es una frontera de «alarma temprana» que se proyecta desde el Estrecho de Behring hasta Hawai; luego hasta las Islas Galápagos (Ecuador), la Isla de Pascua (Chile) y cruza el Canal de Magallanes hasta Las Malvinas. De allí asciende hasta el Centro de Atlántico en las Islas Azores (Portugal) y se proyecta hasta Islandia, regresando por el norte polar hasta el Estrecho de Behring. Spykman era partidario de la intervención y de la Doctrina Monroe: América Latina es una Zona de Contención de rivales extracontinentales y debe retenerse a través de un mercado panamericano y acuerdos de defensa (1954).

- Alexander Seversky. Estudió el poder aéreo. Consideraba que el poder marítimo y el poder terrestre estaban en equilibrio por la guerra fría (1950). Ese equilibrio estaba por romperlo la Unión Soviética con poderosas flotas aéreas de aviones Tupolev y Aero Flot. El poder aéreo permitía romper los cercos terrestres, los Estados tapón y los controles de puertos, pasos y mares. Seversky dividió el mundo en tres grandes «Zonas Aéreas».

1. La zona aérea de Estados Unidos y su espacio de reserva: América del Norte, Central y América del Sur. Las tres Américas son consideradas como las reservas geográficas de la industria de Estados Unidos.

2. La zona aérea de la Unión Soviética que se proyecta hasta el África como reserva. Considera a China como zona de influencia que la distraerá hacia el Asia.

3. Zona de decisión aérea: los espacios industriales de ambas potencias; Estados Unidos y la Unión Soviética (1954).

Seversky construye su teoría cuando Europa estaba en plena reconstrucción (19451972). No obstante que Europa se se encontraba reconstruyendo la Eurozona Aérea estaba bajo control de los Aliados (OTAN) y bajo la dirección de Estados Unidos.

- Samuel Cohen. Norteamericano. Entre 1982 y 1991, Cohen, ex Presidente de la Asociación de Geógrafos de su país, creó una teoría apropiada a la post-guerra fría (1990 hasta nuestros días). Cohen consideró una Teoría de la Jerarquía de los Espacios del globo terrestre. El primer lugar en la jerarquía lo ocupan las rutas comerciales marítimas de mayor frecuencia de navegación. El segundo lugar es ocupado por las rutas terrestres de comercio intraeuropeo, desde Madrid hasta Estocolmo y Rusia, y desde Venecia y Ámsterdam hacia el Mar Negro. La tercera jerarquía de espacios geográficos la ocupan los países de lenguas y etnias comunes:

1. Espacio Latino: Italia - España - Francia Portugal.

2. Espacio Germánico: Alemania - Holanda Dinamarca - Suecia - Noruega, Irlanda y Finlandia.

3. Espacio Anglo Americano: Estados Unidos - Inglaterra - Irlanda - Escocia - CanadáAustralia y Nueva Zelandia.

4. Espacio Chino: Taiwán - Norte de Indonesia.

5. Espacio Eslavo: Costa del Báltico - Polonia - Yugoslavia - Checoslovaquia y Eslovaquia, por afinidad geográfica Rumanía. 
6. Espacios Independientes: Japón, Tailandia, Vietnam, Laos, Camboya, Malasia, Indonesia y Filipinas, que no han podido tener una autoridad supranacional común en toda su existencia, autoridad supranacional como la Unión Europea, Parlamento Regional, Integración Regional, etc.

7. Espacios de Conflicto: $\mathrm{O}$ «Shatterbelt», son los espacios como el Medio Oriente cuyo gas y petróleo causan incertidumbre y juegos de poder entre las potencias de hoy. Venezuela, Bolivia y Colombia serían espacios de conflicto en América Latina.

8. Espacios de Transición: Es el grupo de países del centro de Europa: Estonia, Letonia, Lituania, Polonia, Hungría, Rumanía, Ucrania y países de la ex Yugoslavia.

Los Euroespacios de transición han debilitado la influencia de Rusia en Europa, fortalecido a Alemania en la Europa de los 25 y debilitado a la Alianza Estados Unidos - Inglaterra y su influencia en la Europa Atlántica.

La cuarta jerarquía de espacios son los Estados-Nación, es decir el lugar de las potencias mundiales. Los Estados Potencias también experimentan una jerarquía de potencia de primer, segundo, tercer orden, etc., de acuerdo a tamaño de PBI Nacional; generación de tecnologías innovativas (número de patentes por cada millón de habitantes), tamaño de población y logro educativo; tamaño de territorio; acceso a mares (¿bitrimarítimo?); disponibilidad de energía, gas, petróleo y minerales estratégicos; reservas de energía (gas, petróleo, carbón); estado movilizable de la población; salud de la población (la CIA considera que los rusos nacen enfermos, viven enfermos y mueren temprano); y, número de ingenieros, médicos, físicos y científicos por cada millón de habitantes en comparación con otras potencias rivales.

\section{CONCLUSIONES Y RECOMENDACIONES}

1. La geopolítica es una ciencia multidisciplinaria. Nació en Suecia y Noruega y se desarrolló en Inglaterra y Estados Unidos. La geopolítica es la ciencia que estudia la distri- bución del poder y los recursos escasos entre países, estados y agrupaciones de estados.

2. El Instituto Peruano de Geopolítica (IPEGE) ha creado materiales para formular una estrategia de un Perú bioceánico, bisagra entre MERCOSUR, Asia y Brasil. El mayor autor de los estudios de geopolítica del Perú es el General Edgardo Mercado Jarrín.

3. La teoría del Poder Marítimo (Mahan) fue desplazada por la Teoría del Poder Terrestre (Mackinder). Al mismo tiempo la Teoría del Poder Aéreo (Seversky), precedió a una Teoría Superior: La Jerarquía de los Espacios del Siglo XXI (Samuel Cohen, 2002).

4. La teoría de la Jerarquía de los Espacios del Planeta de Cohen revela con exactitud el mundo de la post-guerra fría (1990-2005). Perú posee aún la ventaja de ser un espacio independiente capaz de aliarse con Brasil, los Países Árabes y forjar un espacio independiente en el tercer mundo. Mercado Jarrín considera que el Pacífico brinda al Perú más oportunidades que el Atlántico para el siglo XXI.

5. Puno. Se ha calculado que posee tres depósitos de gas del tamaño de Camisea (37 trillones de pies cúbicos). Bolivia posee 52 y Venezuela 150. Perú podría pasar a ser el segundo país en reservas de gas en América Latina sumando las reservas de Aguaitía, la Costa Norte y la reservas de Puerto Tortugas (Chiclayo).

6. Plan de 50 años. El Perú necesita un Plan o Proyecto Nacional de 50 años, Proyecto que es Normal en Japón, aunque Alemania planifica para 200 años.

7. No se ha creado aún una Teoría Geopolítica apropiada para el Perú. La Maestría en Desarrollo y Seguridad Nacional puede contribuir a producir los cimientos de un Proyecto Nacional, una Teoría de la Seguridad Territorial y alianzas de estatura estratégica para nuestro país.

\section{BIBLIOGRAFÍA}

Mercado Jarrin, E. La revolución geoestratégica. Lima, CEPEI, Konrad Adenauer Stiftung, IPEGE, agosto 2001. 
Duguin, A. La gran guerra de los continentes. En www.red-vertice.com/anv/D053M

Golveri do Couto E., Silva. Geopolítica do Brasil. Río de Janeiro, 1981.

Giudice Baca, Víctor. La región translima. Revista de Economía de la Facultad de Economía de la UNMSM, Lima - Perú, 2004.

Instituto Peruano de Geopolítica y Estrategia (IPEGE). Ver Revista Semestral.
Lacoste, Yves. Dictionaire de Géopolitique. París, Ed. Flammarion, 1993.

Real Instituto Elcano. Oil in Eurasia (Petróleo en Eurasia). Tomado del Centro de Estudios Estratégicos de Washington, DC., 2004. Ver aquí varios artículos en línea con el buscador del Real Instituto Elcano. 
